\title{
Población extranjera residente en México. Caracterización socio-demográfica y laboral 1990 - 2010*
}

\section{Foreign population living in Mexico. A sociodemographic and labor characterization, 1990 - 2010}

\author{
Ana Melisa Pardo Montaño \\ Departamento de Geografía Económica, Instituto de Geografía, \\ Universidad Nacional Autónoma de México. \\ Correo electrónico: analissa18@gmail.com \\ Claudio Alberto Dávila Cervantes \\ Facultad Latinoamericana de Ciencias Sociales FLACSO, México. \\ Correo electrónico: claudio.davila@flacso.edu.mx
}

\begin{abstract}
Resumen: el objetivo es determinar las principales características socio-demográficas de los extranjeros residentes en México, el mercado laboral en el cual se insertan y su distribución geográfica. Se trata de un estudio descriptivo, transversal y comparativo a partir de los datos de los Censos de Población y Vivienda de 1990, 2000 y 2010 de México. Se concluye que, en general, los extranjeros residentes en México, presentan distintas características sociodemográficas, las cuales dependen de los lugares de origen. Se encontró un patrón de inserción residencial, principalmente en el centro del país y en algunos estados de la frontera con Estados Unidos.
\end{abstract}

Palabras clave: extranjeros, México, inserción laboral, inserción residencial, inmigrantes.

Recibido: junio 2017

\begin{abstract}
: the objective is to determine the main socio-demographic characteristics of the foreign population living in Mexico, the labor market in which they insert and their geographic distribution. This is a descriptive, cross sectional and comparative study using data from the Mexico Population and Housing Census in 1990, 2000 and 2010. We conclude that in general foreigners living in Mexico have different socio-demographic characteristics related to their places of origin. We also found a residential insertion pattern, mainly in the center region of the country and in some border northern states.
\end{abstract}

Keywords: foreigners, Mexico, labor insertion, residential insertion, immigrants.

\section{Aceptado: julio 2017}

*Investigación realizada gracias al apoyo del proyecto Conacyt Problemas Nacionales: "Política y Gestión migratoria en México: Cambios recientes e impacto sobre la población extranjera” y al programa UNAM-DGAPAPAPIIT IA300717 “Cambios en la política migratoria mexicana e impactos en la transformación del espacio”. 


\section{Introducción}

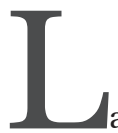

migración internacional es un tema ampliamente trabajado en los últimos años. Por lo general se hace referencia a las continuas oleadas migratorias de países en desarrollo, especialmente hacia Estados Unidos y Europa. Sin embargo, en fechas recientes, la migración interregional, especialmente entre países latinoamericanos como México, Argentina, Venezuela, entre otros, ha tomado mayor relevancia. Esto puede ser ocasionado tanto por la continua vigilancia en la frontera de Estados Unidos, principal destino de muchos de estos migrantes, el aumento de los requerimientos para solicitudes de visas en países europeos, como por la actual crisis económica que se vive a nivel mundial, lo que genera que la población comience a buscar rutas alternativas hacia lugares distintos a los que históricamente han recibido mayor cantidad de migración.

En el caso de México, en los últimos años también se han incrementado tanto la proporción de extranjeros ${ }^{1}$ que recibe, como la procedencia de los mismos. Por lo general, es reconocido el flujo de centroamericanos que transitan por este país con el fin de cruzar hacia Estados Unidos (Castillo, 2003). Sin embargo, una parte de este flujo se establece en México. Pero además del incremento de población centroamericana, en los últimos años, se ha presentado un crecimiento tanto del flujo de españoles, como de población procedente de Argentina, Cuba o Colombia, principalmente.

Considerando lo anterior, el objetivo de la presente investigación es determinar las principales características socio-demográficas de los extranjeros residentes en México, el mercado laboral en el cual se insertan dentro del país, así como su distribución geográfica. Para cumplir con este objetivo, en la primera parte se expone una breve revisión bibliográfica para presentar algunos de los principales estudios, que se han realizado sobre la inmigración hacia México; en segundo lugar se analizan las principales características socio-demográficas, por nacionalidad, de la población extranjera residente en México, además de su inserción al mercado laboral y los principales lugares de residencia, para lo cual se utilizan datos del Instituto Nacional de Estadística y Geografía (INEGI) de los Censos de Población y Vivienda de 1990, 2000 y 2010; y por último, se presentan algunas consideraciones finales y lineamientos para futuras investigaciones sobre inmigración en México.

1 En el caso de esta investigación se entenderán los extranjeros o inmigrantes en México como sinónimos. Algunos autores como Rodríguez y Cobo (2012), explican que el Censo de Población y Vivienda no especifica características como la población naturalizada o la descendencia mexicana, sino que se centra en el lugar de nacimiento. En el caso de esta investigación, se considera que, aunque estos temas deben ser analizados en el tema de la migración, otro elemento importante que no consideran los datos censales, es el año de llegada o el tiempo de residencia en el país, elemento que puede interferir en las distintas relaciones que viven los inmigrantes con su lugar de destino y las consecuencias que dichas relaciones pueden tener. Sin embargo, aún con las limitaciones la fuente de información permite tener un panorama general de las características de esta población. 


\section{Estudios sobre migración extranjera en México}

Las investigaciones sobre migración en México se han centrado principalmente en la expulsión de mexicanos hacia Estados Unidos; el paso de los centroamericanos, que también tienen como destino final el vecino país; y más recientemente la migración de retorno de mexicanos. Sin embargo, México también es un país receptor de migrantes, donde desde décadas pasadas han llegado distintos grupos por razones laborales, de negocios, formación profesional e incluso refugiados que huyen de la violencia en sus países de origen (Cobo y Rodríguez, 2012)

Como explica Rodriguez (2010a), durante el siglo XX, a diferencia de otros países, como Argentina y Venezuela, en los cuales la inmigración era un factor común, en México se dio el fenómeno contrario, donde el incremento de la emigración hacia Estados Unidos fue la tendencia predominante, especialmente a partir del Programa Bracero $^{2}$. Existen muchas investigaciones que han estudiado la migración de mexicanos hacia ese destino (Durand \& Massey, 2003; Portes, Guarnizo y Landolt, 2003; Criado, 2007, Bustamante, 2015), al igual que otras que se enfocan en estudiar la transmigración de centroamericanos (Castillo, 2000; Rodriguez e Iñiguez, 2005), donde sobresalen los guatemaltecos, hondureños y salvadoreños, como los grupos con mayores flujos de paso por México hacia Estados Unidos. Sin embargo, los estudios sobre la inmigración en México son más recientes y menos comunes.

En relación a los extranjeros residentes en México, se han realizado investigaciones sobre algunos colectivos migratorios. Tal es el caso por ejemplo de los españoles residentes en México, (Lida, 1994; Pla Brugat, 2001; Gil, 2010; Cobo, 2010), la mayoría de ellos refugiados o asilados; la población cubana en México (Rojas, 2000; Martinez y Bobes, 2010) o la argentina (García Canclini, 1998).

Trabajos recientes como el de Cobo (2010), quien se enfoca en los españoles residentes en México utilizando los datos del Censo de Población y Vivivienda de 2000, enfatiza en las características sociodemográficas de este grupo poblacional y su inserción en el mercado laboral (principalmente en empleos profesionales), considerando las diferencias generacionales y la disminución de este grupo de acuerdo a esta fuente de información.

En cuanto a los cubanos en México, el trabajo de Martinez y Bobes (2010) tambien se enfoca en las características sociodemográficas y su inserción al mercado laboral, destacando principalmente que se trata de mujeres en edades de 21 a 40 años, con un alto nivel de escolaridad y con una gran concentración geográfica y económica.

Otra perspectiva desde la cual se ha analizado la población migrante residente en México, es a través de la contextualización de la población calificada. En este sentido Castaños (2011) recopila, información a cerca de los migrantes científicos en México, enfocándose no sólo en sus características, sino en la forma como se adaptan al país de recepción, sus principales áreas de trabajo y sus aportes mas importantes, como un proceso de vinculación e intercambio de capital humano.

Un aporte metodológico lo realiza Rodriguez (2010b), quien subraya la relevancia de analizar las fuentes de información disponible para estudiar esta población, mencionando como las más importantes: los censos de población y vivienda, las fichas de registro de

\footnotetext{
${ }^{2}$ Acuerdo laboral celebrado entre México y Estados Unidos en 1942, con el objetivo de población mexicana laborara en Estados Unidos, en el sector agrícola.
} 
extranjeros ubicadas en el Archivo General que permiten estudiar esta población desde 1950, la Encuesta Nacional de Ocupación y Empleo, el registro nacional de extranjeros, las estadísticas de extranjeros naturalizados (Instututo Nacional de Migración), entre otras. En dicho documento el autor remarca las ventajas y limitaciones sobre las fuentes de información, entre las que destaca las pocas fuentes existentes para hacer trabajos de este tipo.

En general, para analizar la población extrajera residente en México, los datos mas utilizados son los censos de población y vivienda, realizados por el Instituto Nacional de Estadística y Geografía (INEGI), en los cuales, entre muchos otros aspectos, se recoge información sobre el lugar de nacimiento de los individuos, la cual será utlizada en esta investigación.

\section{Material y métodos}

Se trata de un estudio descriptivo, transversal y comparativo. Como se mencionó previamente, la información se obtuvo principalmente de los Censos de Población de 1990, 2000 y 2010 del Instituto Nacional de Estadística y Geografía (INEGI) en México. Se consideraron las principales características sociodemográficas de la población extranjera en México, agrupando por su lugar de procedencia. De acuerdo a dichas características, se observaron regiones que comparten ciertas características de acuerdo al lugar de origen de dicha población.

A partir de estas regiones se realizó un análisis de correspondencia múltiple, técnica estadística multivariante que permite analizar gráficamente las relaciones de un conjunto de variables de carácter categórico, con el propósito de asociar las principales características sociodemográficas, y laborales de los migrantes residentes en México y su región de origen. En este caso, se consideraron las variables: región de procedencia, sexo, edad, escolaridad y estatus laboral.

El análisis de correspondencia forma parte de los métodos estadísticos multivariados de reducción de dimensiones basados en la descomposición en valores singulares (Greenacre, 2010). ${ }^{3}$ Este método permite mostrar relaciones entre variables que están compuestas por varias categorías a partir de resultados obtenidos en una tabla

\footnotetext{
${ }^{3}$ En general se parte de un conjunto $m$-dimensional de puntos denotados por $x_{i}(\operatorname{con} \mathrm{i}=1,2, \ldots, \mathrm{n})$, con pesos $w_{i}$ asignados al í-esimo punto y con la métrica entre puntos definida por la matriz diagonal $D_{q}$ con valores positivos $q_{p}, \ldots, q_{m}$ en la diagonal. Estos puntos se pueden proyectar ortogonalmente hacia un subespacio de menor dimensión que ajuste adecuadamente, donde el ajuste se mide por la suma de cuadrados ponderada
}

entre los puntos $x_{i}$ y sus proyecciones $\stackrel{u}{X}, \sum_{i} w_{i}\left(X_{i}-\stackrel{u}{X}\right)^{T} D_{q}\left(X_{i}-\stackrel{u}{X}\right)$ de la siguiente manera:

1. Recoger los puntos como las filas de la matriz $\mathrm{X}$ de dimensión $n \times m$ y los pesos del vector $w$ de dimensión $n \times 1$ y en la diagonal de la matriz $D_{w}$.

2. Centrar $\mathrm{X}$ con respecto a su columna ponderada de promedios: $Y=\left(I-1 w^{T}\right) X$. Puede mostrarse también que el subespacio óptimo necesariamente contiene el promedio ponderado, o centroide, de los puntos, de tal forma que se centran los puntos alrededor del centroide desde el inicio.

3. Realizar una descomposición en valores singulares de $\mathrm{Y}$ al multiplicar sus filas por las raíces cuadradas de los pesos y sus columnas por las raíces cuadradas de los elementos de la métrica; después se calcula la descomposición usual sin ponderar y se transforma la solución de la siguiente forma; 
de contingencias y lleva a una representación gráfica, la cual se conoce como mapa por sus propiedades espaciales de distancia, donde las columnas y los renglones se representan como puntos (Greenacre, 2010). Estos puntos representan vectores de valores relativos en columnas o en filas, expresados de forma relativa a sus marginales, mientras las marginales mismas se usan como ponderadores, llamados masas, dando importancia relativa a los respectivos puntos de las filas o columnas. Las distancias entre los vectores se definen como distancias chi-cuadradas, las cuales son distancias euclideanas ponderadas basadas en el supuesto que la varianza en cada fila o columna es aproximadamente proporcional a la media (Greenacre, 2010). Finalmente la calidad de la representación de la matriz de datos se mide, como en el método de análisis de componentes principales, en términos de un porcentaje de la varianza explicada.

Este método es una forma versátil de reducción de dimensión y debe sus propiedades a la flexibilidad lograda al ponderar las columnas y las filas de forma proporcional a sus marginales y al concepto dual de utilizar los inversos de estas marginales para definir las distancias chi-cuadradas entre los puntos (Greenacre, 2010). Como el mismo autor menciona, entre las principales ventajas que ofrece el análisis de correspondencia destaca que puede presentarse, en un espacio porcentual, la tabulación cruzada simple de variables categóricas múltiples; representa no sólo las relaciones entre filas y columnas, sino también las relaciones entre las categorías tanto de las filas como de las columnas; y, lo más importante, es que puede ofrecer una representación conjunta de categorías de filas y columnas en la misma dimensionalidad, lo que permite identificar grupos caracterizados por atributos muy relacionados. Entre sus principales limitaciones destaca que es una técnica descriptiva, la cual no permite realizar contrastaciones de hipótesis y no cuenta con un método para determinar concluyentemente el número de dimensiones apropiado, pero que en este caso, da lugar a la realización de hipótesis surgidas de dicho análisis de identificación de grupos de migrantes residentes en México que comparten ciertas características sociodemográficas y laborales.

Las variables sociodemográficas que se utilizan en este estudio son: sexo (hombre o mujer); edad quinquenal (de 0 a 80 años y más); país de origen de la población extranjera en México; escolaridad (agrupada en sin escolaridad, primaria incompleta, primaria completa, secundaria completa, bachillerato completo y licenciatura o más); población económicamente activa y población económicamente inactiva; sector de actividad (primario, secundario o terciario); y situación en el trabajo (empleado, jornalero, patrón, trabajador por su cuenta o trabajador sin pago en negocio familiar). Aunque como se verá más adelante, para el análisis de correspondencia éstas variables fueron agrupadas en otras categorías.

En relación a la inserción residencial, se realizó el análisis a nivel estatal, considerando las nacionalidades de origen en cinco grupos principales, como se verá más adelante. En este caso, el análisis se elaboró solamente para el año 2010.

$$
D_{w}^{1 / 2} Y D_{q}^{1 / 2}=U D_{\alpha} V^{T} \quad \mathrm{~F}=D_{w}^{1 / 2} U D_{\alpha}
$$

Donde la matriz $\mathrm{F}$ contiene las coordenadas principales de los puntos, es decir, sus posiciones respecto a sus ejes. El análisis de correspondencia utiliza este algoritmo un par de veces. (Greenacre, 2010). 


\section{Características socio-demográficas de los extrajeros residentes en México}

INEGI explica que un asunto significativo del fenómeno migratorio es el reducido número de países en los que se concentra la inmigración a nivel mundial. Según esta misma fuente, desde 1990, más de 86\% de los inmigrantes internacionales se concentran en once países (INEGI, 2010). En el caso de México, no se trata del surgimiento de un nuevo destino, ya que desde hace varios años se ha presentado migración hacia México de forma significativa. Lo que llama la atención es el incremento que la inmigración ha sufrido en los últimos años; cuestión que puede estar relacionada con las dificultades con las que se encuentra esta población para establecerse en los destinos históricos, como por ejemplo Estados Unidos, donde la continua vigilancia en la frontera o las distintas leyes migratorias dificultan la migración.

De acuerdo con la información presentada por el INEGI, en las últimas décadas, el número de extranjeros residentes en México ha ido en aumento. Mientras en 1990, la población extranjera representaba el $0,4 \%$ del total de la población censada, para el 2000 alcanza 0,5\%; mientras que el mayor crecimiento se dio en la última década, llegando en 2010 al 0,9\% aproximadamente, lo que equivale casi a un millón de personas extranjeras residiendo en México (Cuadro 1). La mayoría de esta población procede de Estados Unidos y Centroamérica; no obstante, en los últimos años, también ha aumentado la población proveniente de distintos países de Suramérica. Aunque los porcentajes no son tan elevados como en el caso de otros flujos migratorios, es relevante considerar la importancia de la población extranjera principalmente por las particularidades de cada nacionalidad (edad, mayor o menor nivel educativo, documentación, etc.).

Cuadro 1. Extranjeros residentes en México 1990 - 2010

\begin{tabular}{lrrrrrr}
\hline \multirow{2}{*}{ País } & \multicolumn{2}{c}{$\mathbf{1 9 9 0}$} & \multicolumn{2}{c}{$\mathbf{2 0 0 0}$} & \multicolumn{2}{c}{$\mathbf{2 0 1 0}$} \\
\cline { 2 - 7 } & Población & Porcentaje & Población & Porcentaje & Población & Porcentaje \\
\hline Total & $\mathbf{3 3 9 7 8 0}$ & $\mathbf{1 0 0 . 0 0}$ & $\mathbf{5 1 9 7 0 7}$ & $\mathbf{1 0 0 . 0 0}$ & $\mathbf{9 6 8 2 7 1}$ & $\mathbf{1 0 0 . 0 0}$ \\
Estados Unidos & 198230 & 58.34 & 358399 & 68.96 & 739918 & 76.42 \\
Guatemala & 42380 & 12.47 & 29156 & 5.61 & 31888 & 3.29 \\
España & 24620 & 7.25 & 21334 & 4.11 & 20727 & 2.14 \\
Argentina & 4340 & 1.28 & 6625 & 1.27 & 14171 & 1.46 \\
Colombia & 4660 & 1.37 & 6639 & 1.28 & 12832 & 1.33 \\
Cuba & 2660 & 0.78 & 7267 & 1.40 & 11822 & 1.22 \\
Venezuela & 1460 & 0.43 & 3024 & 0.58 & 10786 & 1.11 \\
Canadá & 3100 & 0.91 & 7245 & 1.39 & 10208 & 1.05 \\
Honduras & 1990 & 0.59 & 4203 & 0.81 & 9980 & 1.03 \\
El Salvador & 5060 & 1.49 & 5786 & 1.11 & 8864 & 0.92 \\
Francia & 4190 & 1.23 & 5723 & 1.10 & 8533 & 0.88 \\
China & 1160 & 0.34 & 1847 & 0.36 & 7486 & 0.77 \\
Alemania & 4560 & 1.34 & 5632 & 1.08 & 7033 & 0.73 \\
Otro país & 41370 & 12.18 & 56827 & 10.93 & 74023 & 7.64 \\
\hline
\end{tabular}

Fuente: Elaboración propia con base en datos del INEGI, muestras del diez por ciento del XI Censo General de Población y Vivienda, 1990; XII Censo General de Población y Vivienda, 2000, y Censo de Población y Vivienda, 2010. 
El país que presenta mayor porcentaje de residentes en México es Estados Unidos, tendencia que se ha mantenido desde 1990 y que ha ido en aumento (véase Cuadro 1). Esto principalmente porque existe una fuerte presencia de personas nacidas en Estados Unidos cuyos padres (o alguno de ellos) son de origen mexicano, además de la población adulta mayor jubilada procedente del vecino país que se establece en algunos estados mexicanos (Lizárraga, 2008). En segundo lugar, se encuentran los guatemaltecos, aunque su participación ha disminuido proporcionalmente en los últimos años, pasando de 12,5\% en 1990 a 3,3\% en 2010. Un gran porcentaje de ellos son refugiados de la guerra civil en los años ochenta; otro tanto se establecen en Chiapas dedicándose al trabajo agrícola, además de aquellos que utilizan a México como país de tránsito hacia Estados Unidos, pero que por distintas razones se han establecido de manera permanente en México (Paredes, 2009). Por su parte, los españoles fueron la primera comunidad europea inmigrada al territorio mexicano, y aunque al igual que los guatemaltecos han disminuido su importancia porcentual, la migración en números absolutos muestra la importancia de esta comunidad dentro del territorio mexicano. Por su parte, otros países suramericanos han aumentado significativamente el número de residentes en México en fechas recientes; tal es el caso de los colombianos, que, aunque porcentualmente su participación se ha mantenido estable, en números absolutos, casi se ha triplicado entre 1990 y 2010. Algo similar sucede en otras nacionalidades, como por ejemplo Cuba, Venezuela y Argentina.

En cada caso, sin embargo, la migración presenta características distintas a nivel socio-demográfico y laboral, las cuales analizaremos a continuación.

\section{Distribución por sexo y edad de los extranjeros residentes en México (1990-2010)}

A nivel general, en 1990 la población extranjera residente en México estaba conformada por un 49,7\% de hombres y 50,3\% de mujeres; en 2000 y en 2010, la situación cambia aumentando la proporción de hombres (50,3\% y 50,6\% de hombres y un $49,7 \%$ y $49,4 \%$ de mujeres respectivamente). Estos porcentajes se reflejan en el índice de masculinidad ${ }^{4}$ el cual, para 1990 fue de 98,9, en 2000 se incrementó a 101,4 y en 2010 fue de 102,5, lo que significa que en relación a la población extrajera en el país se encuentran actualmente 102 hombres por cada 100 mujeres aproximadamente.

Sin embargo, existen diferencias entre nacionalidades. En el caso de Estados Unidos, se ha presentado una tendencia del indicador similar a la general, aumentando de 1990 a 2010 de 95,2 a 103,3. Sin embargo, China presentó un índice de masculinidad de 169,8 en 1990, de 89,8 en 2000 y 142,4 hombres por cada 100 mujeres en 2010 indicativo de una gran fluctuación por sexo. Destaca también el caso de Argentina, que cuenta con 128,3 hombres por cada 100 mujeres en 2010. También los datos reflejan nacionalidades con mayores proporciones de mujeres, como es el caso de El Salvador y Colombia cuyo índice es de 70 aproximadamente o el de Guatemala o Venezuela, ambos inferiores a 88 hombres por cada 100 mujeres. Finalmente, el caso de Cuba es interesante ya que en 1990 presentaba un índice de 73,9, el cual ha aumentado hasta

${ }^{4}$ El Índice de Masculinidad es una medida demográfica utilizada para verificar las diferencias entre los sexos, el cual consiste de dividir la población o los eventos de los hombres entre la población o los eventos de las mujeres y multiplicar ese cociente por cien. 
situarse en un nivel de 94 hombres por cada 100 mujeres, acercándose cada vez más a una distribución equitativa de hombres y mujeres en el país.

La población extranjera residente en México contaba con una estructura particularmente joven tanto en 1990 como en 2000; la mediana de la edad de la población extranjera era menor (14 años en ambos años), en comparación con la del resto de la población (20 y 22 años respectivamente) $)^{5}$ (INEGI, 2005). Como se observa en la gráfica 1, esta estructura no ha sufrido cambios significativos para 2010 (gráfica $1)^{6}$, ya que $56,34 \%$ de la población nacida en el extranjero y residente en el país, se encontraba en el grupo de edad de 0 a 14 años. En el caso de la población originaria de Estados Unidos residente en México, un pequeño porcentaje de esta población son jubilados que deciden desplazarse hacia México, los cuales se ubican principalmente en estados fronterizos y algunos del centro del país como Guanajuato o Jalisco (Lizárraga, 2008); pero de acuerdo con los datos censales, los grupos de edad en los que se ha concentrado mayor población proveniente de ese país desde 1990 es de 0 a 19 años con poco más del 70,8\% de los inmigrantes en ese año, alcanzando poco más de $80 \%$ en 2010 (ver, anexo1), lo que hace suponer que en su mayoría se trata de población nacida en Estados Unidos de origen mexicano que por distintas razones, regresa al país?

Gráfica 1. Distribución por edad y sexo de los extranjeros residentes en México, 2010

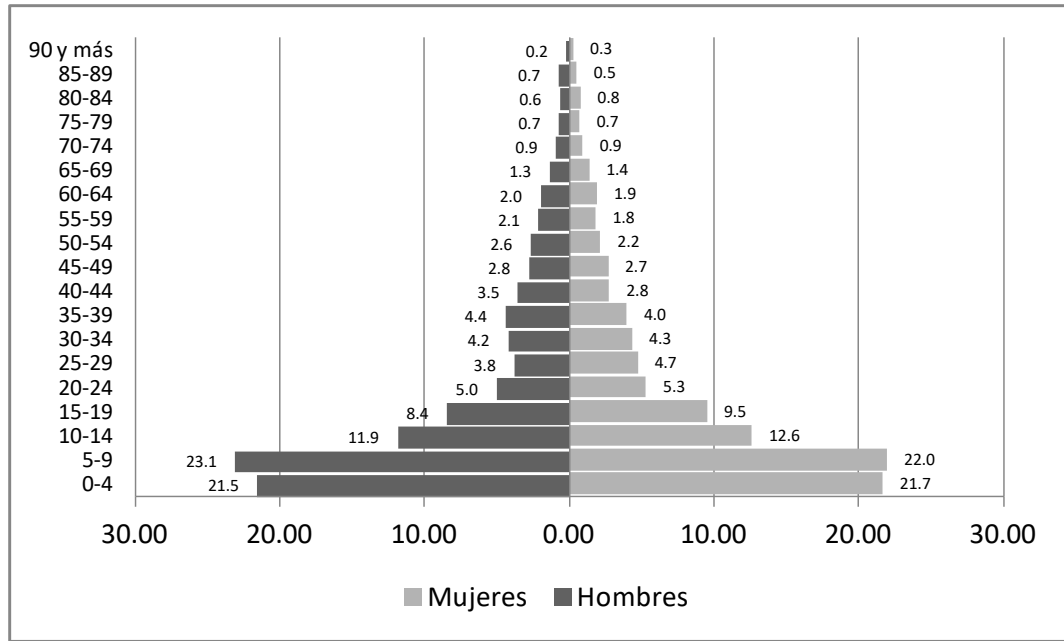

Fuente: Elaboración propia con base en datos del Censo de Población y Vivienda de 2010.

\footnotetext{
${ }^{5}$ Sin embargo, es importante considerar que la estructura por edad cambia de acuerdo con el origen de los migrantes. De acuerdo con el INEGI (2010), la edad mediana para los procedentes de Estados Unidos es de 11 años, para la población procedente de Europa es de 49 años, 39 años para los procedentes de África y Asia y 32 para los originarios de Oceanía.

${ }^{6}$ Dado que la estructura de población extranjera en México no ha sufrido cambios significativos desde 1990 a 2010, se presenta solamente la pirámide de población para el periodo más reciente (2010).

${ }^{7}$ Por lo general, los estudios sobre retorno explican que la deportación, es uno de los principales factores que incrementan la población con familiares de origen mexicano, pero nacidos en Estados Unidos, se desplacen a México.
} 
Al examinar la estructura por edad, sin considerar en el análisis el caso de Estados Unidos debido a su elevada participación en el fenómeno y que casi el 50\% de ésta, se trata de población retornada o con familia procedente de este país, el porcentaje de población joven disminuye considerablemente en todos los años analizados (ver gráfica 2). En cifras, poco más del 10\% de los extranjeros se encuentran entre los 0 y los 14 años (16,8\% en 1990, 10,5\% en 2000 y 2010), mientras que poco más del $50 \%$ se encuentran entre los 20 y los 49 años (47,5\% en 1990, 53\% en 2000 y $56,5 \%$ ) y con una tendencia creciente en últimos años. Estas son las principales edades laborales, lo cual tiene implicaciones considerables para los lugares de salida, ya que es la población en edades productivas, la que abandona los países de origen y se desplaza a México.

Las diferencias entre la gráfica 1 y 2, permiten observar el peso de los jóvenes provenientes de los Estados Unidos en el total de la población extranjera residente en México desde hace más de 20 años, situación que se recomienda sea analizada con mayor detalle en investigaciones futuras.

Gráfica 2. Distribución por edad y sexo de los extranjeros

(sin considerar Estados Unidos) residentes en México, 2010

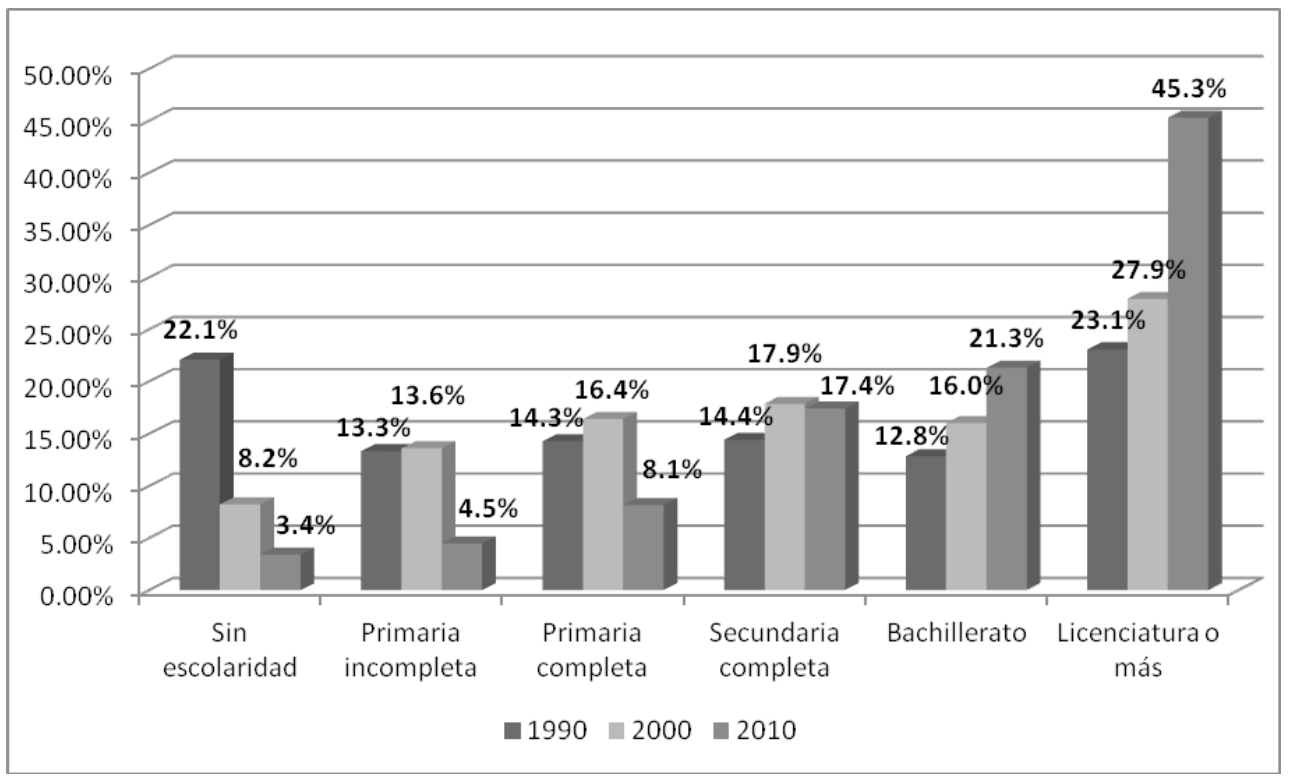

Fuente: Elaboración propia con base en datos del Censo de Población y Vivienda de 2010.

En cuanto a la estructura por edad de otras nacionalidades, se observó que la población guatemalteca, presenta una mayor distribución de su población, concentrándose desde 1990 poco más del 60\%, principalmente en edades jóvenes (10 a 39 años). Los procedentes de España, se encuentran en edades de 35 a 44 años (18,5\% en 2010) o aquellos con más de 60 años (con más de 40\% desde 1990). Mientras que los procedentes de países latinoamericanos como Colombia, Argentina, Cuba y Venezuela, se encuentran principalmente en edades laborales (25 a 49 años) con una participación mayor al 50\% en todos los casos y todos los años. 


\section{Nivel de escolaridad ${ }^{8}$}

En relación a la escolaridad (gráfica 3), llama la atención que un porcentaje considerable de población extranjera residente en México se agrupa entre quienes no tienen escolaridad, tienen primaria incompleta o cursaron hasta la primaria completa, aunque este porcentaje ha disminuido a lo largo del tiempo (49,7\% en 1990, 38,2\% en 2000 y $16 \%$ en 2010). Otro elemento importante, es el alto porcentaje de población con bachillerato y estudios de licenciatura o más, el cual ha ido en aumento con el paso de los años (36\% en 1990, 43,9\% en 2000 y 66,6\% en 2010).

Gráfica 3. Escolaridad de la población nacida en el extranjero y residente en México, 1990, 2000 y 2010

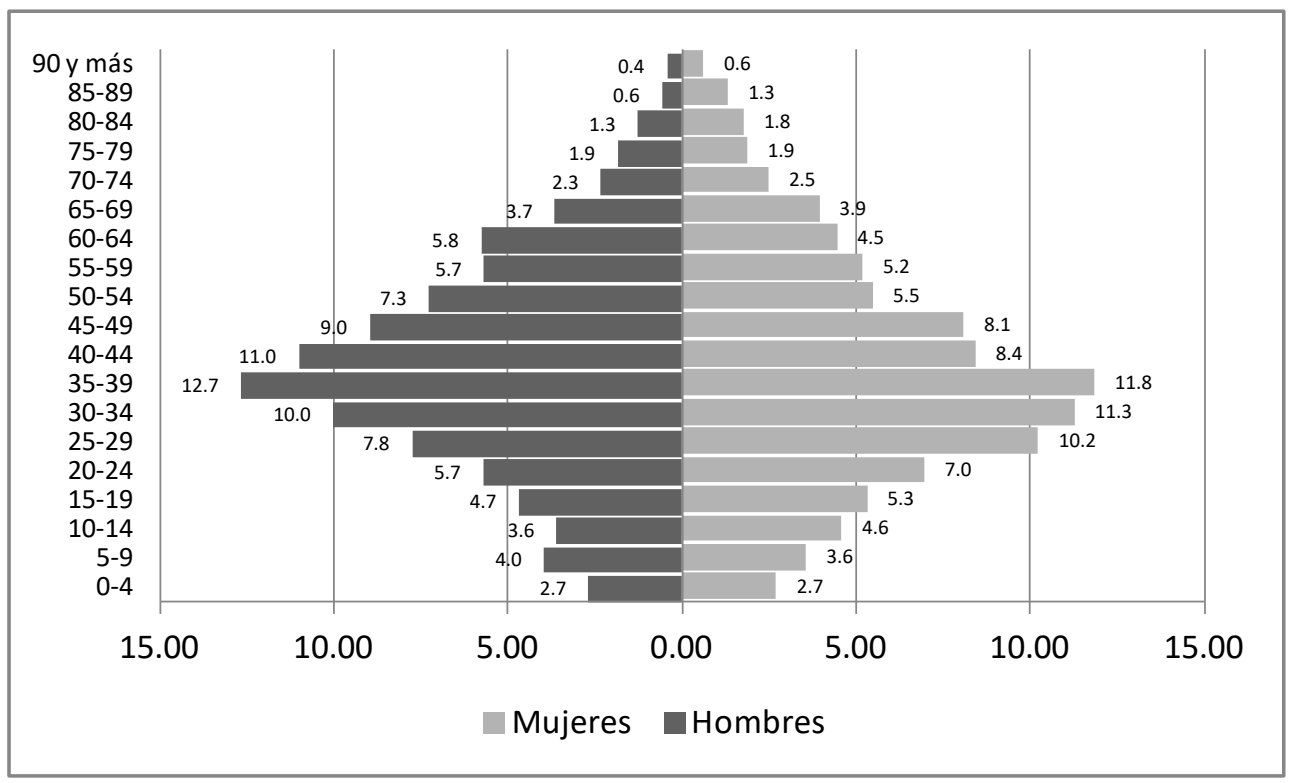

Elaboración propia con base en datos de los Censos de Población y Vivienda de 1990, 2000 y 2010 de INEGI.

Sin embargo, al analizar lo que sucede por nacionalidades, se observan varias diferencias. Los migrantes procedentes de Centroamérica son los que presentan mayores niveles de población sin escolaridad, tal es el caso de Guatemala $(58,6 \%$ en 1990, 24,3\% en 2000 y 28,3\% en 2010), El Salvador (alrededor de 8,1\% en los 3 años) y Honduras (4,9\% en $1990,2,8 \%$ en 2000 y 3,6\% en 2010). Por otro lado, los colombianos presentan menos de un $0,75 \%$ de población sin escolaridad desde 1990, y en 2010 no tienen población sin escolaridad; en otros casos, los porcentajes son bajos históricamente como por ejemplo en Argentina (2,4\% a 0,4\% de 1990 a 2010), España (4\% en 1990 a $0,6 \%$ en 2010$)$ y Venezuela $(0,95 \%$ a $0,8 \%$ en 2010$)$.

En el caso de la población oriunda de España, se observan diferencias en cuanto a la escolaridad. Mientras que la población sin escolaridad o hasta con primaria completa,

\footnotetext{
${ }^{8}$ Para el análisis de la escolaridad, se consideró solamente la población de 18 años y más.
} 
apenas era de 7,8\%, la población con estudios de licenciatura o más alcanza el 51,7\% en 2010. Casos similares se observan en los países latinoamericanos como Venezuela, Colombia, Argentina y Cuba9 . Los venezolanos, por ejemplo, contaban en 2010 con el mayor porcentaje de población con estudios de licenciatura y más (83\%), seguidos por los colombianos $(80,5 \%)$, los argentinos $(72,8 \%)$ y los cubanos $(66 \%)$.

Estas diferencias, en cuanto a los niveles de escolaridad, se deben principalmente al tipo de migración de cada país. Mientras que la población centroamericana y específicamente la guatemalteca, en muchos casos se encontraba de paso hacia Estados Unidos, con el fin de mejorar sus condiciones económicas y por distintas circunstancias establecen su hogar permanente o semipermanente en México, la población proveniente de América del Sur y del Caribe, se trata, en muchos de los casos, de empresarios que se establecen en México o de estudiantes que migran a este país a cursar licenciaturas o posgrados, lo que se ve reflejado en sus altos niveles de escolaridad y en la poca población con estudios de secundaria o menos.

\section{Características laborales}

Después de analizar algunas de las características socio-demográficas de la población extranjera en México, se consideraron algunas características laborales como: si los migrantes pertenecen a la población económicamente activa (PEA) o no, cuál es su situación en el trabajo, en qué sectores de actividad se ubican estos migrantes y el número de horas trabajadas.

De acuerdo con el INEGI, la PEA es entendida como el grupo de personas de 12 años y más que en la semana de referencia realizaron algún tipo de actividad económica (población ocupada), además de aquellos que buscaron incorporarse en algún empleo (población desocupada); mientras la Población Económicamente Inactiva (PEI), es el grupo de personas de 12 años y más que en la semana de referencia no participaron en ninguna actividad económica, pero tampoco buscaron incorporarse en el mercado laboral y que incluye estudiantes, personas jubiladas o pensionados, e individuos que por cualquier razón (salud, invalidez, etc.) no realizan actividad económica de ningún tipo.

A nivel general, como se observa en la gráfica 4, desde 1990 más de la mitad de la población extranjera residente en México se encuentra inactiva (con un máximo de $61,4 \%$ en 1990), con una ligera tendencia a disminuir, ubicándose en un 54,7\% en 2010.

${ }^{9}$ Los datos presentados en el caso de Cuba coinciden los resultados del trabajo de Martínez y Bobes (2010), cuando hacen referencia al alto nivel educativo de esta población en 2000. 
Gráfica 4. Condición de actividad de la población nacida en el extranjero y residente en México, según datos del INEGI, 1990, 2000

$$
\text { y } 2010^{10}
$$

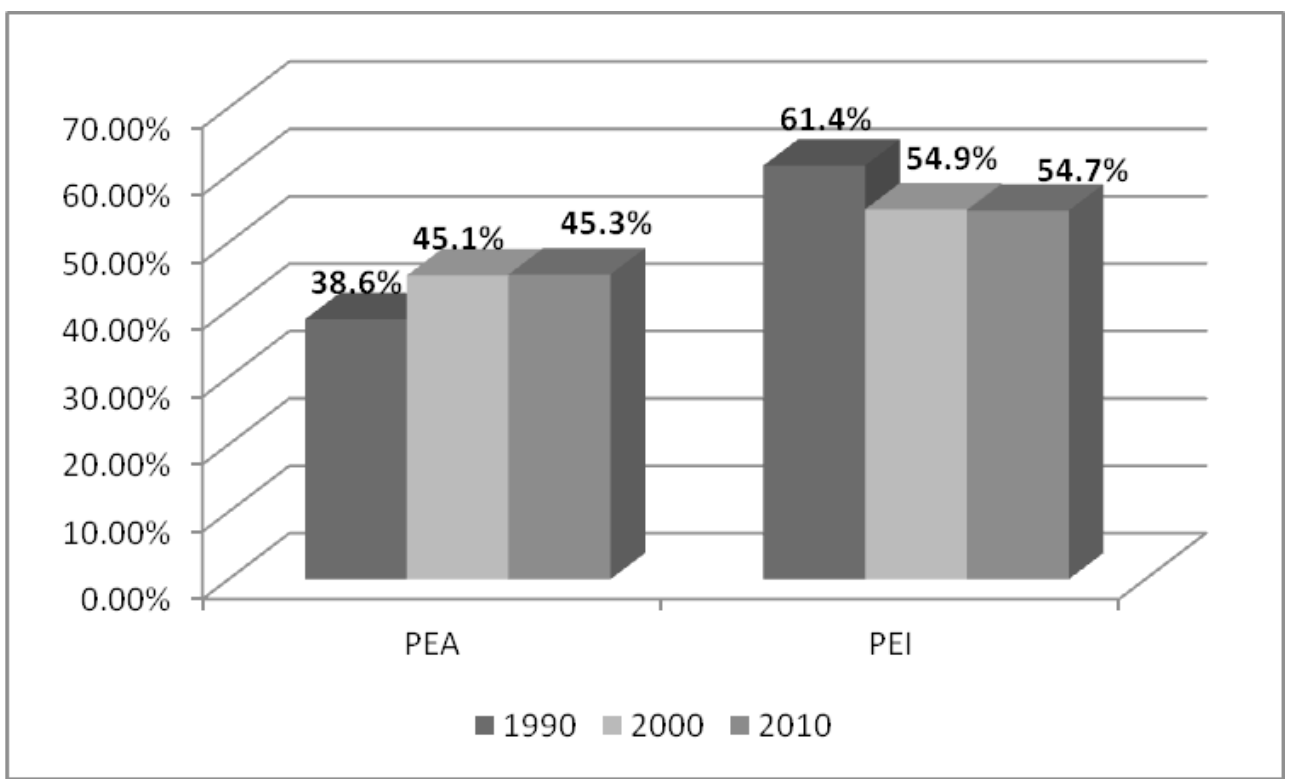

Elaboración propia con base en datos de los Censos de Población y Vivienda de 1990, 2000 y 2010 de INEGI.

En el caso particular de la población procedente de Estados Unidos y España, presentan desde 1990 a 2010, una mayor proporción de población económicamente inactiva $(66,5 \%$ y 50,3\%, en 2010 respectivamente). Esto, porque, como se mencionó, en el caso de la población oriunda de Estados Unidos, la mayor cantidad de población se ha ubicado desde 1990 en edades muy jóvenes (más del 50\% de la población se encuentra en edades de 0 a 9 años), mientras que en el caso de España más del 54,4\% de la población es mayor de 50 años y probablemente esté conformada por individuos jubilados o pensionados.

En la población procedente de Latinoamérica y el Caribe se presenta una situación interesante. En 1990 la población procedente de Guatemala, Colombia, Cuba, Venezuela, Honduras y El Salvador, presentaban una población mayoritariamente inactiva (todos con porcentajes mayores a 51,5\%) (Anexo 3). Para 2000 y 2010, esta situación cambia ya que la mayoría de la población de estos países forma ahora parte de la PEA con porcentajes elevados, destacando los cubanos $(64,8 \%)$, los colombianos $(64,5 \%)$ y los hondureños $(62,2 \%)$ en 2010 . Al igual que en el caso anterior, esto se debe a la composición por edad de la población latinoamericana residente en México, en la mayoría de los casos, se trata de personas en edades laborales. Por otra parte, en 2010 los porcentajes de población económicamente activa desocupada son bajos en todos los

\footnotetext{
${ }^{10}$ Para el análisis de las características laborales, se considera la población de 12 años y más.
} 
casos, 2,5\% para Venezuela, 2,3\% para Estados Unidos y Honduras, 1,8\% para España y $0,4 \%$ para Canadá.

En relación al sector de actividad, la mayoría de la población se agrupa entre aquellos que trabajan en el sector terciario ${ }^{11}$ con un poco más del $68 \%$ desde 1990 y con una tendencia creciente de participación en este sector ya que en 2010 alcanza casi un $75 \%$ (gráfico 5). Los datos anteriores aumentan en el caso de la población proveniente de España $(81,6 \%)$, Colombia $(83,2 \%)$ y Cuba $(92,2 \%)$ en 2010 . Sobresale el caso de Guatemala, que, aunque más de la mitad de la población trabaja en este sector, 35,6\% labora en el sector primario. Esto último se debe a que un porcentaje considerable de la migración guatemalteca a México se ubica en la región sureste de Chiapas, un área agrícola en la cual uno de los principales productos es el café (Castillo, 2001).

Gráfico 5. Sector de actividad de la población nacida en el extranjero y residente en México, 1990, 2000 y 2010

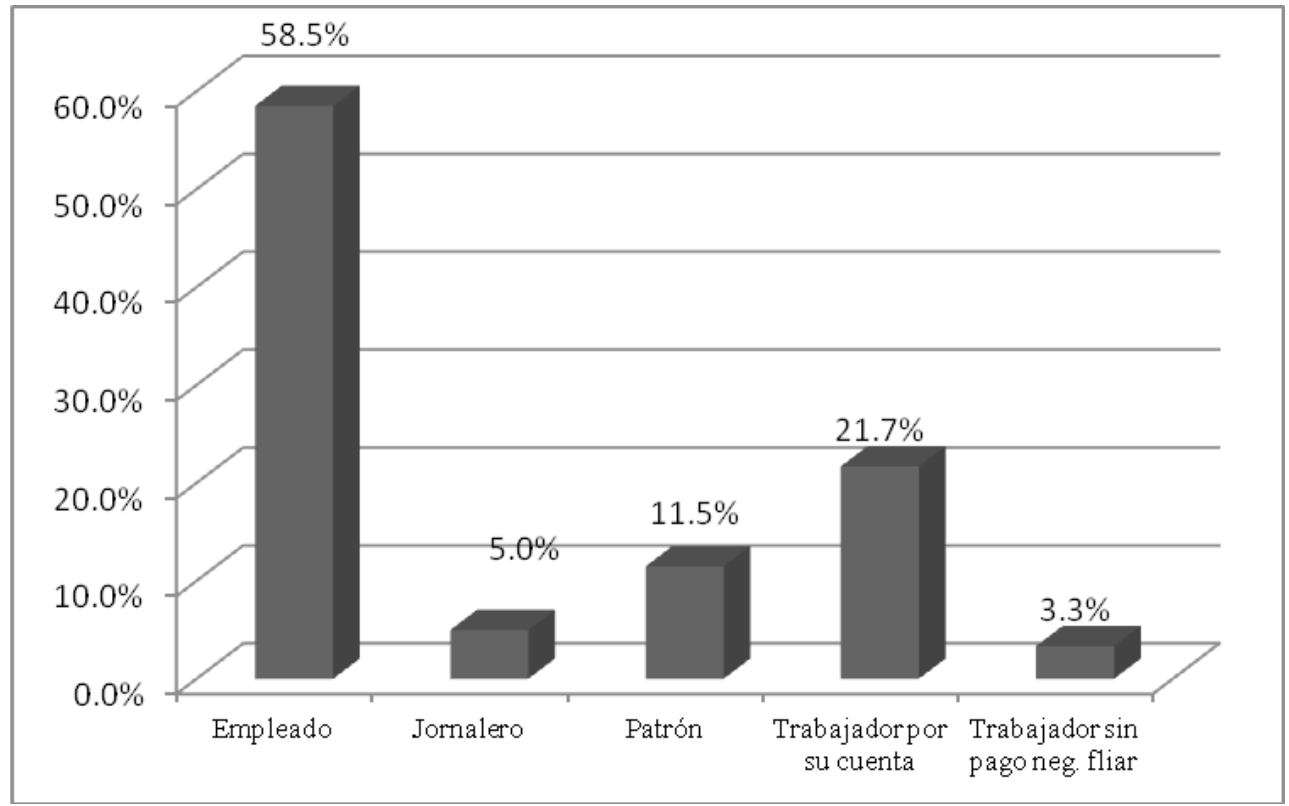

Fuente: Elaboración propia con base en datos de los Censos de Población y Vivienda de 1990, 2000 y 2010 de INEGI.

Respecto al sector de actividad en el cual labora esta población actualmente, se observa que más de la mitad de los extranjeros en México trabajan como empleados y en menor porcentaje como trabajadores por su cuenta (ver gráfico 6). El porcentaje de empleados aumenta en el caso de la población proveniente de Estados Unidos (67,7\%) y de Venezuela (65,9\%). Guatemala presenta diferencias considerables en cuanto a la distribución de su población de acuerdo al sector de actividad, 30,3\% laboran como

\footnotetext{
${ }^{11} \mathrm{El}$ sector terciario, de acuerdo a la clasificación del INEGI, incluye todas las unidades económicas que ofrecen algún servicio
} 
empleados, 35,5\% como jornaleros y $26,1 \%$ como trabajadores por su cuenta. En el caso de los jornaleros, llama además la atención el caso de Honduras con 7,8\%. Los españoles, de igual manera trabaja principalmente como empleados, el resto se distribuye principalmente entre quienes laboran como patrones $(27,5 \%)$ y como trabajadores por su cuenta $(24 \%)$.

Gráfico 6. Situación en el trabajo de la población nacida en el extranjero y residente en México, 2010

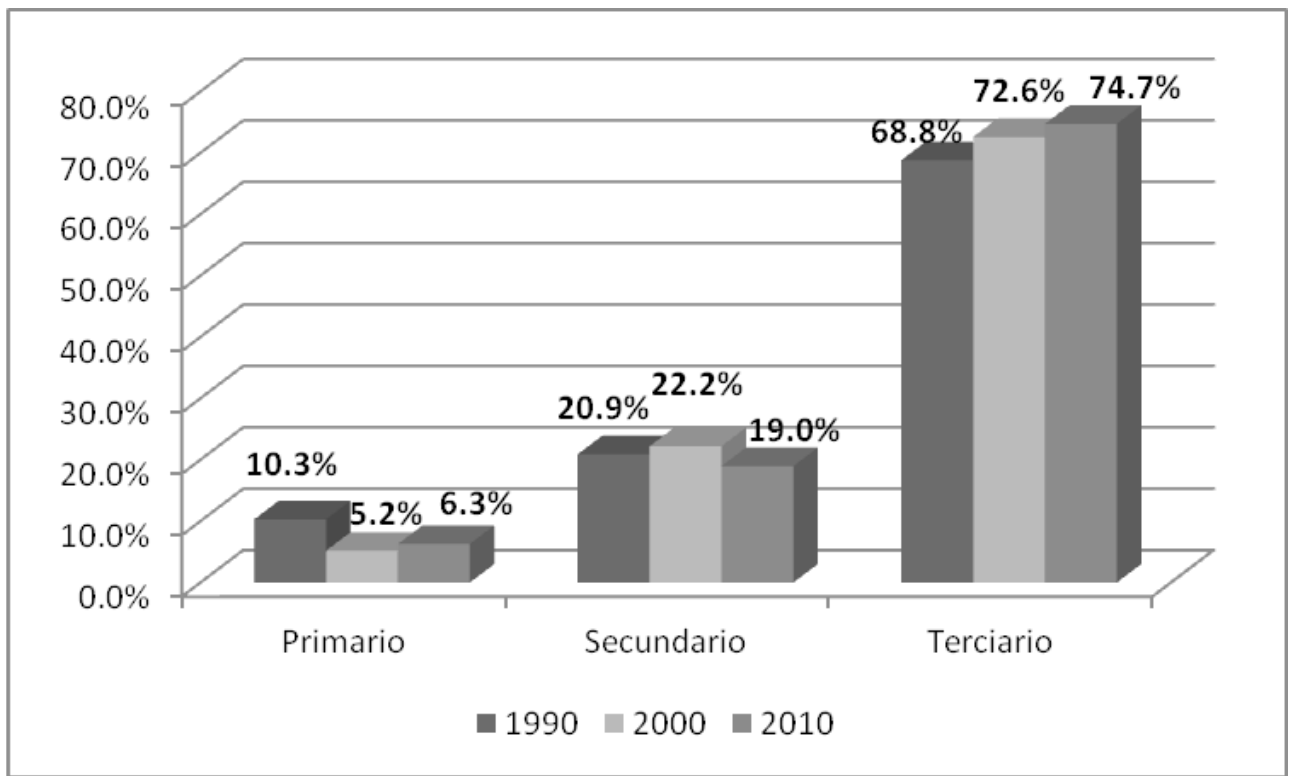

Fuente: Elaboración propia con base en datos del Censo de Población y Vivienda de 2010.

En relación a las horas trabajadas, en promedio los extranjeros en 2010 laboran 45 horas semanales. Los que más laboran son los chinos (56 horas en promedio) y los salvadoreños (53 horas), mientras que la población que trabaja menos horas del promedio, proviene de Estados Unidos (41 horas) y de Cuba (43 horas).

\section{Análisis de correspondencia}

$\mathrm{Al}$ analizar las características socio-demográficas y laborales, se observan algunos grupos de extranjeros con elementos en común. Por ejemplo, de manera general, se puede mencionar que la población procedente de Estados Unidos cuenta con población muy joven y con menor escolaridad que los procedentes de otros países. Otro grupo es el de los provenientes de América Latina y el Caribe, específicamente Argentina, Cuba, Colombia y Venezuela, en el cual predomina la población en edades laborales, ocupadas y de alta escolaridad. La población procedente de Centroamérica (Guatemala, Honduras y El Salvador), entre los que predomina la población económicamente activa, con niveles de escolaridad menores y donde un porcentaje considerable se dedica a actividades relacionadas con el sector primario de la economía. Por último, se 
encuentran los procedentes de España, población más envejecida con poco menos de la mitad de población económicamente activa y con poco más de la mitad de población femenina.

Para analizar las relaciones entre las características mencionadas, se realizó un análisis de correspondencia múltiple para cada uno de los censos, con la intención de analizar, no sólo si existe relación entre las variables mencionadas, sino si han existido cambios en esta asociación a lo largo del tiempo. Como se mencionó previamente este tipo de análisis tiene como objetivo y principales ventajas, ofrecer una representación conjunta de categorías de distintas variables que permite identificar grupos caracterizados por atributos muy relacionados. Para dicho análisis se excluye el caso de los Estados Unidos, dado que el alto porcentaje de población procedente de dicho país sesga las relaciones entre las variables de interés.

De acuerdo a los resultados del análisis de correspondencia, se puede observar, que desde 1990, ha existido una estrecha relación entre variables como el sexo y la situación laboral (ver anexo 4). En el caso de los hombres, la mayor relación está con la categoría de PEA, mientras que, para mujeres, la mayor relación se da con las inactivas (PEI). De igual manera, en 1990 existía una relación entre las regiones de procedencia, la edad y la escolaridad; en cambio, para 2000 la principal relación entre estas variables se presenta entre la región y la escolaridad; mientras que para 2010 se evidencia cierta relación entre las regiones de procedencia y la edad. Los resultados del análisis, para el 2010, se observan en la gráfica siguiente:

Gráfica 7. Análisis de correspondencia extranjeros en México, 2010

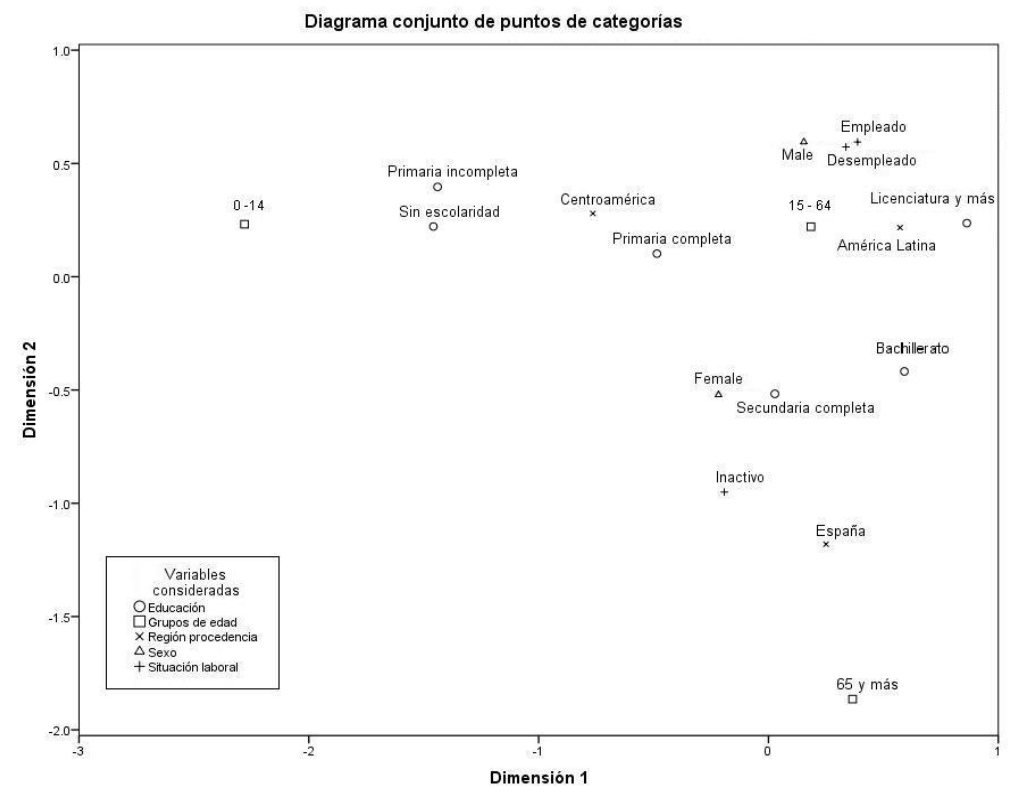

Normalización principal por variable.

Fuente: Elaboración propia con base en datos del Censo de Población y Vivienda de 2010. 
Por otra parte, considerando la región de procedencia, también se observan distintas relaciones entre las variables analizadas. Mientras los procedentes de países de Latinoamérica y el Caribe (sin Centroamérica), se asocian más con la categoría de educación "Licenciatura y más", con el grupo de edad de 15 - 64 años y con la PEA, resultado consistente con los grupos observados previamente; los procedentes de países de Centroamérica, se acercan más las categorías de "sin escolaridad" y "primaria incompleta", lo cual corrobora lo observado en el análisis inicial, de que los centroamericanos cuentan, en promedio, con niveles de escolaridad menores al resto. Por último, los procedentes de España, se asocian más con la población más envejecida (65 años y más) y con las mujeres inactivas.

Después de analizar las principales características de la población extranjera considerando los países de origen, en el siguiente apartado, se relacionan los estados en los cuales se ubica dicha población.

\section{Inserción residencial de los extranjeros en México}

Las personas nacidas en el extranjero residen en todas las entidades federativas de México (mapa 1), principalmente en zonas urbanas.

Se observa que los estados con mayor población extranjera en los años analizados han sido: Baja California (con un porcentaje superior al $10 \%$ en 1990 y de $12,9 \%$ en 2000 y 2010), Chihuahua (variando entre 7,5\% y 9,1\% aproximadamente), Jalisco (con un valor máximo de 10,4\% en 2000 y de 8,1\% en 2010), Estado de México (con un promedio de 5,4\%) y Michoacán (que incrementó su participación de 3,9\% en 1990 a 4,7\% en 2010) (ver Anexo 5); estados que, o comparten frontera con Estados Unidos o hacen parte de la zona tradicional de expulsión de población. Llaman la atención los casos del Distrito Federal (cambiando de 16,3\% en 1990 a 7,7\% en 2010), Tamaulipas (de $8,1 \%$ a $6,8 \%$ ), Nuevo León (de $4,2 \%$ a 3,1\%) y Chiapas $(8,1 \%$ en 1990 a 3,3\% en 2010), los cuales presentaron una tendencia notablemente decreciente de población extranjera en el periodo de estudio. Las entidades federativas con la menor cantidad de esta población son: Tlaxcala (con una participación inferior a 0,3\%), Campeche (que presentó una tendencia decreciente de 2,4\% a 0,6\%), Tabasco (con niveles inferiores a $0,6 \%$ ), Yucatán (con un promedio de $0,7 \%$ ) y Colima (con niveles menores a $0,9 \%$ ), que algunos se tratan de estados cercanos a la frontera sur de México.

La población procedente de Estados Unidos se ha concentrado desde 1990 hasta 2010 principalmente en Baja California (con porcentajes superiores a 15,2\%), Chihuahua (10,9\% o mayores) y Tamaulipas ( $8,4 \%$ a $13 \%$ en el periodo estudiado) estados que hacen parte de la frontera norte del país; los guatemaltecos, hondureños y salvadoreños se han concentrado principalmente en Chiapas (con porcentajes superiores a 61,1\%,34,6\% y $22,4 \%$ respectivamente), estado que comparte frontera con la región Centroamericana; los españoles, colombianos y argentinos, se concentran principalmente en el centro del país, en el Distrito Federal (con porcentajes superiores a 39,3\%, 21,3\% y 40,5\% respectivamente) y el Estado de México (con cifras mayores a 8\%, 22,1\% y 11,2\% respectivamente); en el caso de los cubanos, aunque un porcentaje considerable se ubica en el Distrito Federal (29,2\%), llama la atención que otro porcentaje se concentra en la frontera sur de México, en Quintana Roo (12,1\%) y Yucatán (12,6\%); las otras nacionalidades, se encuentran principalmente en la Frontera con Estados Unidos y el centro del país. 


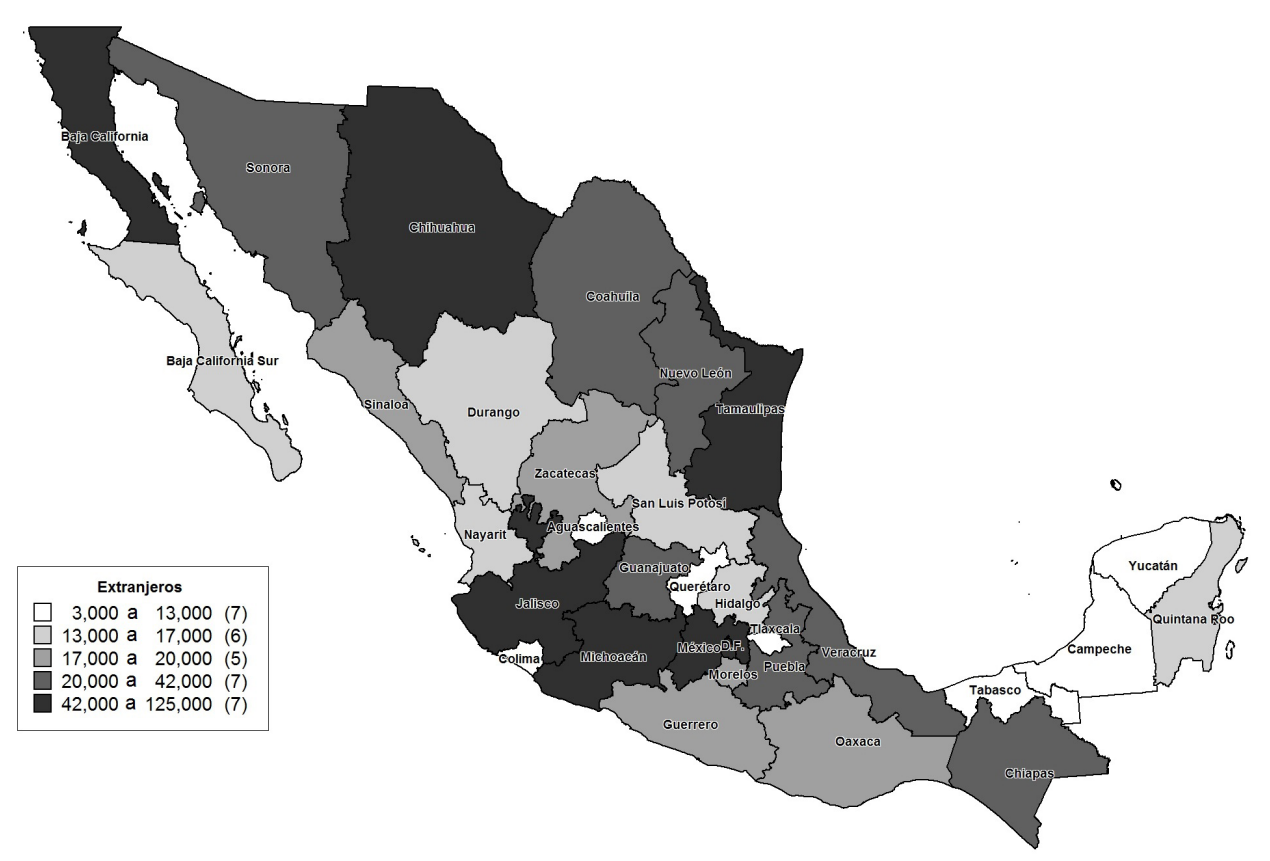

Mapa 1: Estados de residencia de los extranjeros en México en 2010

Fuente: Elaboración propia con base en la muestra del Censo de Población y Vivienda, 2010

\section{Consideraciones finales}

México no es sólo un país de migración de tránsito o de expulsión de población hacia Estados Unidos, sino que en los últimos años se ha convertido en un lugar de atracción de población procedente de distintos países del mundo. La constante relación que tiene con Estados Unidos, con quien comparte frontera, es uno de los principales motivos por los cuales, el mayor porcentaje de los inmigrantes proviene de dicho país (58,3\% en 1990 y 76,4\% en 2010); la estructura por edad de esta población es bastante joven, por lo que puede tratarse de niños y jóvenes que han retornado con sus familiares mexicanos.

Sin considerar la población procedente de Estados Unidos, se observa que la población extranjera en México, en su mayoría tienen altos niveles de escolaridad, se encuentran entre la población económicamente activa y se dedican al sector terciario de actividad económica, aunque aparecen algunas excepciones como el caso de Guatemala, que su principal actividad está relacionada todavía con el sector primario, específicamente con la agricultura.

En cuanto a la distribución geográfica en el país, se observó que la mayoría de los migrantes residentes en México se ubican tanto en la frontera con Estados Unidos como en el centro del país. Aquellos que están localizados en la zona fronteriza, pueden tratarse de inmigrantes que han ingresado al país, con el objetivo de cruzar la frontera hacia Estados Unidos, y que por distintas circunstancias se han establecido en dichos estados. 
Analizando las características sociodemográficas se encontraron regiones que comparten ciertas particularidades. Este el caso de quienes proceden de Estados Unidos y que en su mayoría se trata de población muy joven. La segunda región está conformada por los originarios de países de América Latina y el Caribe (sin Centroamérica) como Colombia, Argentina, Cuba y Venezuela, de donde procede la mayor proporción de población con altos niveles de escolaridad y en edades laborales. La tercera región, es la conformada por centroamericanos principalmente de Guatemala, El Salvador y Honduras, en dicho grupo predominan aquellos con poca escolaridad, jóvenes y que se dedican a actividades del sector primario. Por último, se encuentra el caso de España, población donde prevalecen las mujeres, con altas proporciones de población envejecida y en su mayoría inactiva.

El análisis de la inmigración en México por nacionalidades ha permitido identificar ciertos patrones de acuerdo a los países de procedencia, identificando características socio-demográficas y laborales que pueden ser de utilidad para futuras investigaciones acerca de la inserción de esta población y los retos a los que se enfrenta no sólo México, sino los países de origen, que expulsan principalmente población en edades laborales. En México han predominado los estudios sobre tránsito y emigración hacia Estados Unidos, por lo que se considera necesario incorporar además investigaciones que permitan analizar el impacto que puede tener la población inmigrante en México y la expulsión en los lugares de origen.

\section{Referencias}

Bustamante, J. 2015. La Migración de México a Estados Unidos: de la coyuntura al fondo. Revista Latinoamericana de Población, 1 (1): 89-113.

Castaños Lomnitz, H. 2011. Oleadas de migrantes científicos a México. Una visión general. Universidad Nacional Autónoma de México, Instituto de Investigaciones Económicas, México.

Castillo, Manuel A. 2000. Las políticas hacia la migración centroamericana en países de origen, de destino y de tránsito. Papeles de población. Universidad Autónoma del Estado de México. 6 (24): 133-157.

Castillo, Manuel A. 2001. Los flujos migratorios en la frontera sur de México. En Amérique Latine Historie et Mémoire, Les Cahiers ALHIM.

Castillo, Manuel A. 2003. Los desafíos de la migración centroamericana en el siglo XXI. En Amérique Latine Historie et Mémoire, Les Cahiers ALHIM.

Cobo, S. 2010. Los inmigrantes españoles contemporaneos en México: Una mirada a sus perfiles sociodemográficos y sus patrones de participación laboral. En Ernesto Rodríguez Chávez; María del Socorro Herrera Barreda (coord.) Extranjeros en México. Continuidades y aproximaciones. México. Centro de estudios migratorios. DGE Ediciones. p. 173-197.

Cobo, S. y Rodríguez, E. (2012). Hacia una estimación de los extranjeros residentes en México. Aproximación con base en los registros administrativos del INM. En Ernesto Rodríguez Chávez; Luz María Salazar Cruz; Graciela Martínez Caballero (coord). Construyendo estadísticas. Movilidad y migración internacional en México. México. Centro de Estudios Migratorios y Tilde Editores. pp. 63-88.

Criado Calvo, M. 2007. Inmigración y población latina en los Estados Unidos. Un perfil sociodemográfico. Madrid, Instituto Conplutense de Estudios Internacionales, Universidad Complutense.

Durand, J.; Massey, Douglas. 2003. Clandestinos. Migración México-Estados Unidos en los albores del siglo XXI. México, Miguel Angel Porrua. 
Garcia Canclini, N. 1998. Argentinos en México: una visión antropológica. En Pablo Yankelevich; María Luisa Tarrés. (coord). México, entre exilios-Una experiencia de sudamericanos. México, Secretaría de Relaciones Exteriores (SRE), Instituto Tecnológico Autónomo de México (ITAM), Plaza y Valdés.

Greenacre, Michael J. 2010. Correspondence analysis. Wiley Interdisciplinary Revieres: Computational Statistics. 2(5): pp. 613-619.

Gil, A. 2010. La presencia de españoles en México en el siglo XX. Continuidades y rupturas en una visión panorámica desde el final del porfiriato y hasta los años ochenta, 1910-1980. En Ernesto Rodríguez Chávez; María del Socorro Herrera Barreda. (coord.) Extranjeros en México. Continuidades y aproximaciones. México, Centro de estudios migratorios, DGE Ediciones. pp. 133-172.

INEGI. 1990. XI Censo General de Población y Vivienda. Instituto Nacional de Estadística y Geografía. México.

INEGI. 2000. XII Censo General de Población y Vivienda. Instituto Nacional de Estadística y Geografía. México.

INEGI. 2005. Anexo II Conteo de Población y Vivienda 2005. Disponible en: http://www.inegi.org. $\mathrm{mx} /$ prod_serv/contenidos/espanol/bvinegi/productos/integracion/municipios/mexympios/ MexIICona_6.pdf [Consultado el 19 de febrero de 2016].

INEGI. 2010. Censo de Población y Vivienda. Instituto Nacional de Estadística y Geografía. México.

Lida, Clara Eugenia. 1994. Una inmigración privilegiada. Comerciantes, empresarios y profesionales españoles en México en los siglos XIX y XX. Madrid, Alianza Americana.

Lizárraga Morales, O. 2008. La inmigración de jubilados estadounidenses en México y sus prácticas transnacionales: Estudio de caso en Mazatlán, Sinaloa y Cabo San Lucas, Baja California Sur. Migración y Desarrollo, Red Internacional de Migración y Desarrollo. 11:97-117.

Martínez Pérez, L.; y Bobes León, Velia C. 2010. La inmigración cubana actual en México. Su perfil sociodemográfico e inserción laboral. En Ernesto Rodríguez Chávez; María del Socorro Herrera Barreda. (coord.) Extranjeros en México. Continuidades y aproximaciones. México, Centro de estudios migratorios, DGE Ediciones. pp. 307-330.

Paredes Orozco, G. 2009. Migración de guatemaltecos a México y Estados Unidos a partir de la Encuesta sobre migración en la frontera Guatemala-México 2004: Un análisis de estrategias migratorias. Migraciones internacionales, 5(1), 93-124.

Pla Brugat, D. 2001. La presencia española en México, 1930-1990: caracterización e historiografía. Migraciones E Exilios: Cuadernos de la Asociación para el estudio de los exilios y migraciones ibéricos contemporáneos 2. Pp. 157-188.

Portes, A; Guarnizo, L; Landolt, P. 2003. La globalización desde abajo: Transnacionalismo inmigrante y desarrollo. La experiencia de los Estados Unidos y América Latina. México, FLACSO, Miguel Angel Porrua.

Rodrìguez, E.; e Iñiguez, M. 2005. Flujo de entradas de extranjeros por la frontera sur terrestre de México registradas por el Instituto Nacional de Migración. México. Centro de Estudios Migratorios. Instituto Nacional de Migración.

Rodríguez Chávez, E. 2010a. La inmigración en México a inicios del siglo XXI. En Chávez; María del Socorro Herrera Barreda. (coord.) Extranjeros en México. Continuidades y aproximaciones. México, Centro de estudios migratorios, DGE Ediciones. pp. 89-132.

Rodríguez Chávez, E.. 2010b. Fuentes de información estadística sobre inmigrantes en México. Potencialidades y limitaciones. En Chávez; María del Socorro Herrera Barreda. (coord.) Extranjeros en México. Continuidades y aproximaciones. México, Centro de estudios migratorios, DGE Ediciones.

Rojas, Rafael. 2000. Cuba mexicana: historia de una anexión imposible. México. Secretaría de relaciones exteriores. 


\section{Anexos}

\section{Anexo 1. Distribución por edad y país de nacimiento de los extranjeros residentes en México en 1990, 2000 y 2010}

\begin{tabular}{|c|c|c|c|c|c|c|c|c|c|c|c|c|c|c|c|}
\hline \multicolumn{16}{|c|}{1990} \\
\hline 5 a 9 & $20,4 \%$ & $10,2 \%$ & $1,7 \%$ & $3,5 \%$ & $4,5 \%$ & $0,8 \%$ & $7,5 \%$ & $4,8 \%$ & $5,0 \%$ & $6,1 \%$ & $9,5 \%$ & $4,3 \%$ & $3,9 \%$ & $4,5 \%$ & $14,3 \%$ \\
\hline 15 a 19 & $10,3 \%$ & $14,1 \%$ & $3,2 \%$ & $6,7 \%$ & $3,6 \%$ & $2,3 \%$ & $9,6 \%$ & $4,8 \%$ & $12,1 \%$ & $4,9 \%$ & $3,3 \%$ & $3,4 \%$ & $2,9 \%$ & $5,4 \%$ & $9,1 \%$ \\
\hline 0 a 24 & $4,5 \%$ & $\%$ & $6 \%$ & $6,7 \%$ & $6 \%$ & $3,4 \%$ & $8,9 \%$ & $\%$ & $1,6 \%$ & $12,5 \%$ & $3,8 \%$ & $4,3 \%$ & $3 \%$ & $8,3 \%$ & $5,8 \%$ \\
\hline 25 a 29 & $2,8 \%$ & $10,5 \%$ & $9 \%$ & $9,0 \%$ & $1,5 \%$ & $4,9 \%$ & $12,3 \%$ & $5 \%$ & $4,1 \%$ & $17,6 \%$ & $4,3 \%$ & $12,9 \%$ & $6,1 \%$ & $8,4 \%$ & $5,3 \%$ \\
\hline 10 a 44 & $2,0 \%$ & $5 \%$ & $8 \%$ & $\%$ & $\%$ & $9,4 \%$ & $6,2 \%$ & $\%$ & $6,5 \%$ & $6,3 \%$ & $10,7 \%$ & $6,0 \%$ & $9,6 \%$ & $9,4 \%$ & $4,2 \%$ \\
\hline 45 a 49 & $1,4 \%$ & $9 \%$ & $7,5 \%$ & $12,9 \%$ & $6 \%$ & $7,9 \%$ & $6,8 \%$ & $4,5 \%$ & $5,0 \%$ & $4,7 \%$ & $6,7 \%$ & $6,0 \%$ & $1,2 \%$ & $7,3 \%$ & $3,5 \%$ \\
\hline 50 a 54 & $1,3 \%$ & $2,7 \%$ & $9,5 \%$ & $7,8 \%$ & $3,2 \%$ & $9,8 \%$ & $4,1 \%$ & $4,5 \%$ & $3,5 \%$ & $2,8 \%$ & $7,4 \%$ & $10,3 \%$ & $14,5 \%$ & $5,6 \%$ & $3,2 \%$ \\
\hline 55 a 59 & $2,1 \%$ & $\%$ & $0 \%$ & $5,5 \%$ & $1,5 \%$ & $7,9 \%$ & $0,0 \%$ & $5,5 \%$ & $2,0 \%$ & $1,2 \%$ & $3,6 \%$ & $4,3 \%$ & $4,6 \%$ & $4,5 \%$ & $3,1 \%$ \\
\hline 0 a 64 & $4,1 \%$ & $2,3 \%$ & $10,5 \%$ & $6,2 \%$ & $9 \%$ & $11,3 \%$ & $4,1 \%$ & $3,2 \%$ & $1,0 \%$ & $3,0 \%$ & $7,6 \%$ & $0,9 \%$ & $6,4 \%$ & $4,2 \%$ & $4,4 \%$ \\
\hline 65 a 69 & $2,8 \%$ & $1,2 \%$ & $2 \%$ & $2,3 \%$ & $6 \%$ & $9,4 \%$ & $0,7 \%$ & $13,5 \%$ & $2,0 \%$ & $1,6 \%$ & $2,4 \%$ & $2,6 \%$ & $4,8 \%$ & $4,4 \%$ & $3,2 \%$ \\
\hline
\end{tabular}

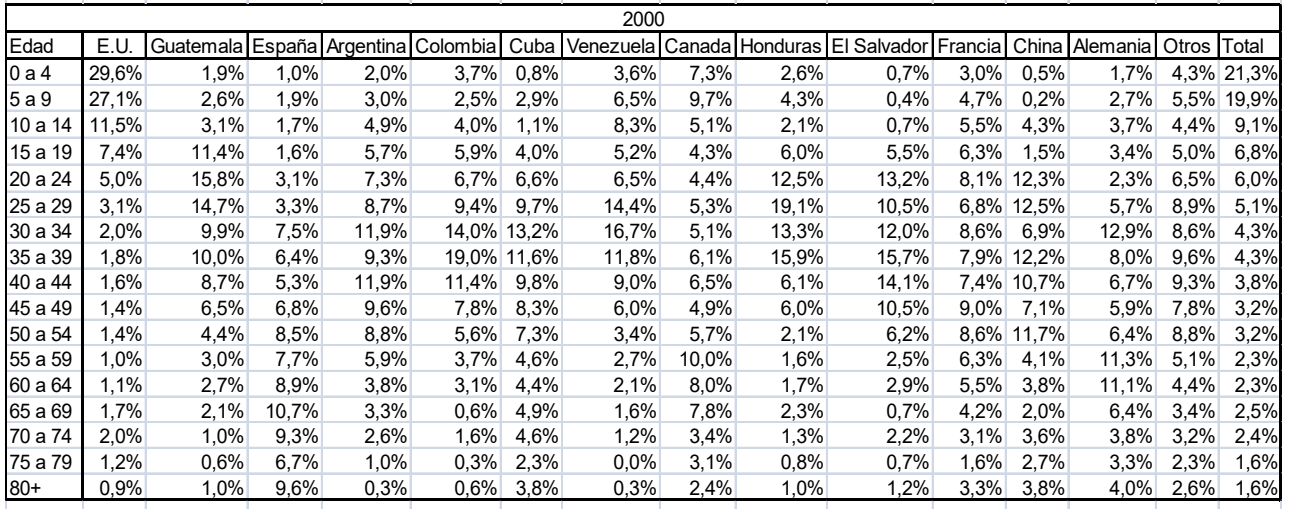

\begin{tabular}{|c|c|c|c|c|c|c|c|c|c|c|c|c|c|c|c|}
\hline \multicolumn{16}{|c|}{2010} \\
\hline Edad & E.U. & Guatemala & España & Argentina & Colombia & Cuba & Venezuela & Canada & Honduras & El Salvador & Francia & China & Alemania & Otros & Total \\
\hline 5 a 9 & $28,3 \%$ & $4,0 \%$ & $5,1 \%$ & $2,5 \%$ & $5,2 \%$ & $1,3 \%$ & $5,5 \%$ & $9,0 \%$ & $2,9 \%$ & $2,3 \%$ & $2,5 \%$ & $1,5 \%$ & $1,4 \%$ & $3,5 \%$ & $22,5 \%$ \\
\hline 15 a 19 & $10,2 \%$ & $10,4 \%$ & $1,6 \%$ & $3,6 \%$ & $2,6 \%$ & $1,8 \%$ & $4,3 \%$ & $3,8 \%$ & $7,1 \%$ & $4,9 \%$ & $4,8 \%$ & $10,3 \%$ & $4,0 \%$ & $4,4 \%$ & $9,0 \%$ \\
\hline 20 a 24 & $4,8 \%$ & $11,1 \%$ & $1,1 \%$ & $5,6 \%$ & $2,5 \%$ & $7,1 \%$ & $5,3 \%$ & $5,6 \%$ & $10,7 \%$ & $4,3 \%$ & $10,5 \%$ & $14,1 \%$ & $5,4 \%$ & $5,2 \%$ & $5,2 \%$ \\
\hline 25 a 29 & $2,8 \%$ & $11,9 \%$ & $3,3 \%$ & $11,6 \%$ & $10,8 \%$ & $10,6 \%$ & $11,3 \%$ & $3,5 \%$ & $17,4 \%$ & $9,3 \%$ & $7,5 \%$ & $8,5 \%$ & $6,3 \%$ & $8,0 \%$ & $4,3 \%$ \\
\hline 40 a 44 & $1,1 \%$ & $9,3 \%$ & $6,3 \%$ & $6,7 \%$ & $12,5 \%$ & $10,0 \%$ & $8,2 \%$ & $6,5 \%$ & $9,7 \%$ & $12,0 \%$ & $8,0 \%$ & $11,0 \%$ & $12,4 \%$ & $11,1 \%$ & $3,2 \%$ \\
\hline 45 a 49 & $1,0 \%$ & $7,4 \%$ & $4,9 \%$ & $8,4 \%$ & $7,5 \%$ & $10,6 \%$ & $6,7 \%$ & $6,3 \%$ & $7,9 \%$ & $11,7 \%$ & $5,4 \%$ & $14,8 \%$ & $13,4 \%$ & $9,5 \%$ & $2,7 \%$ \\
\hline 50 a 54 & $1,2 \%$ & $6,0 \%$ & $5,9 \%$ & $5,4 \%$ & $8,2 \%$ & $8,6 \%$ & $3,7 \%$ & $8,4 \%$ & $2,9 \%$ & $6,5 \%$ & $2,8 \%$ & $7,8 \%$ & $3,3 \%$ & $7,3 \%$ & $2,4 \%$ \\
\hline 55 a 59 & $0,9 \%$ & $3,9 \%$ & $4,9 \%$ & $8,4 \%$ & $3,2 \%$ & $6,2 \%$ & $2,0 \%$ & $9,1 \%$ & $2,3 \%$ & $11,0 \%$ & $10,4 \%$ & $2,0 \%$ & $6,2 \%$ & $5,4 \%$ & $2,0 \%$ \\
\hline 60 a 64 & $1,0 \%$ & $2,6 \%$ & $9,4 \%$ & $5,3 \%$ & $2,8 \%$ & $5,9 \%$ & $2,3 \%$ & $8,3 \%$ & $0,8 \%$ & $4,6 \%$ & $4,9 \%$ & $1,0 \%$ & $3,8 \%$ & $6,4 \%$ & $2,0 \%$ \\
\hline 65 a 69 & $0,6 \%$ & $1,5 \%$ & $7,6 \%$ & $4,4 \%$ & $1,1 \%$ & $7,5 \%$ & $1,5 \%$ & $4,8 \%$ & $0,1 \%$ & $3,4 \%$ & $3,7 \%$ & $0,4 \%$ & $8,6 \%$ & $4,1 \%$ & $1,4 \%$ \\
\hline
\end{tabular}

Fuente: Elaboración propia con base en la muestra del Censo de Población y Vivienda, 2010 


\section{Anexo 2. Escolaridad de la población extranjera residente en México sin considerar los Estados Unidos 1990, 2000 y 2010}

\begin{tabular}{|l|r|r|r|r|r|r|}
\hline \multirow{2}{*}{ Escolaridad } & \multicolumn{2}{|c|}{$\mathbf{1 9 9 0}$} & \multicolumn{2}{c|}{$\mathbf{2 0 0 0}$} & \multicolumn{2}{|c|}{2010} \\
\cline { 2 - 7 } & Frecuencia & \multicolumn{1}{c|}{$\%$} & Frecuencia & \multicolumn{1}{c|}{$\%$} & Frecuencia & \multicolumn{1}{c|}{$\%$} \\
\hline Sin escolaridad & 18360 & $16,6 \%$ & 6468 & $4,9 \%$ & 9641 & $4,9 \%$ \\
\hline $\begin{array}{l}\text { Primaria } \\
\text { incompleta }\end{array}$ & 8920 & $8,1 \%$ & 11163 & $8,4 \%$ & 10869 & $5,6 \%$ \\
\hline Primaria completa & 10330 & $9,3 \%$ & 11467 & $8,7 \%$ & 15763 & $8,1 \%$ \\
\hline $\begin{array}{l}\text { Secundaria } \\
\text { completa }\end{array}$ & 14050 & $12,7 \%$ & 14661 & $11,1 \%$ & 20068 & $10,3 \%$ \\
\hline Bachillerato & 18490 & $16,7 \%$ & 24518 & $18,6 \%$ & 33299 & $17,0 \%$ \\
\hline Licenciatura y más & 40380 & $36,5 \%$ & 63867 & $48,3 \%$ & 105882 & $54,2 \%$ \\
\hline Total & 110530 & $100,0 \%$ & 132144 & $100,0 \%$ & 195522 & $100,0 \%$ \\
\hline
\end{tabular}

Fuente: Elaboración propia con base en la muestra del Censo de Población y

Vivienda, 2010

Anexo 3. Porcentaje de población extranjera por condición de actividad 1990 - 2010

\begin{tabular}{|l|r|r|r|r|rr|}
\hline \multirow{2}{*}{ País de Origen } & \multicolumn{3}{|c|}{ PEA } & \multicolumn{3}{c|}{ PEI } \\
\cline { 2 - 7 } & $\mathbf{1 9 9 0}$ & $\mathbf{2 0 0 0}$ & $\mathbf{2 0 1 0}$ & $\mathbf{1 9 9 0}$ & $\mathbf{2 0 0 0}$ & $\mathbf{2 0 1 0}$ \\
\hline Estados Unidos & 29.4 & 36.2 & 33.5 & 70.6 & 63.8 & 66.5 \\
Guatemala & 43.2 & 48.8 & 59.8 & 56.8 & 51.2 & 40.2 \\
España & 45.0 & 50.0 & 49.7 & 55.0 & 50.0 & 50.3 \\
Argentina & 55.6 & 63.2 & 70.4 & 44.4 & 36.8 & 29.6 \\
Colombia & 35.7 & 54.9 & 64.5 & 64.3 & 45.1 & 35.5 \\
Cuba & 48.8 & 54.5 & 64.8 & 51.2 & 45.5 & 35.2 \\
Venezuela & 46.2 & 50.2 & 57.7 & 53.8 & 49.8 & 42.3 \\
Canadá & 33.3 & 34.9 & 52.8 & 66.7 & 65.1 & 47.2 \\
Honduras & 40.8 & 55.4 & 62.2 & 59.2 & 44.6 & 37.8 \\
El Salvador & 47.8 & 55.6 & 57.4 & 52.2 & 44.4 & 42.6 \\
Francia & 56.4 & 56.6 & 65.1 & 43.6 & 43.4 & 34.9 \\
China & 58.1 & 72.4 & 62.5 & 41.9 & 27.6 & 37.5 \\
Alemania & 53.5 & 56.1 & 62.0 & 46.5 & 43.9 & 38.0 \\
Otro país & 46.7 & 55.5 & 61.7 & 53.3 & 44.5 & 38.3 \\
\hline Total & 38.6 & 45.1 & 45.3 & 61.4 & 54.9 & 54.7 \\
\hline
\end{tabular}

Fuente: Elaboración propia con base en las muestras de los Censos de Población y Vivienda, 1990, 2000 y 2010 de INEGI. 


\section{Anexo 4. Análisis de correspondencia de extranjeros en México, 1990,2000 y 2010}

Análisis de correspondencia y medidas de discriminación en 1990

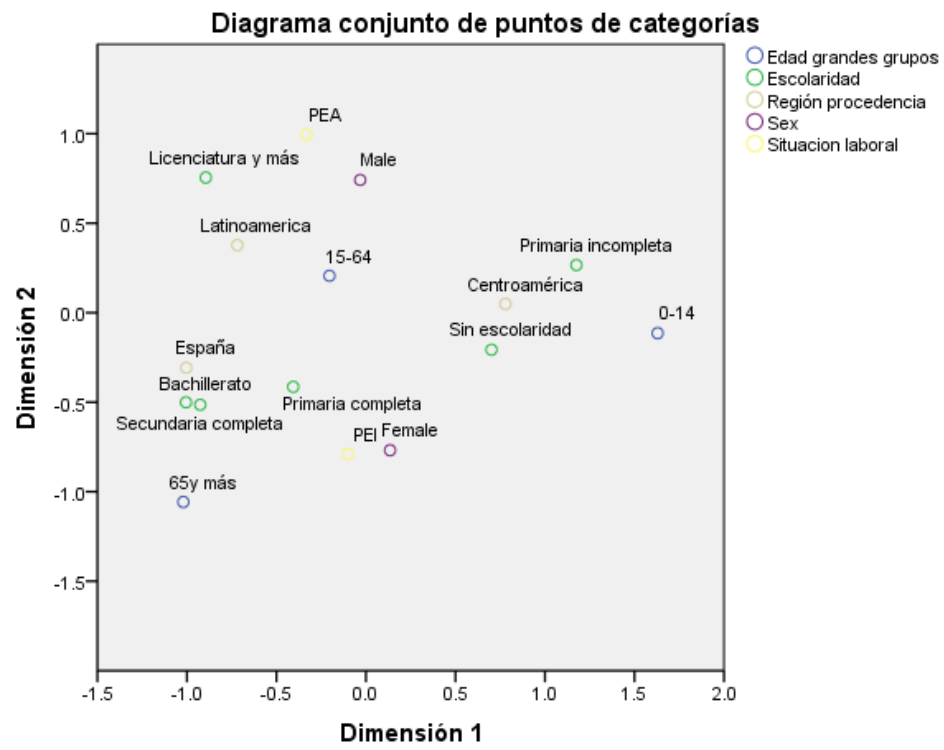

Normalización principal por variable.

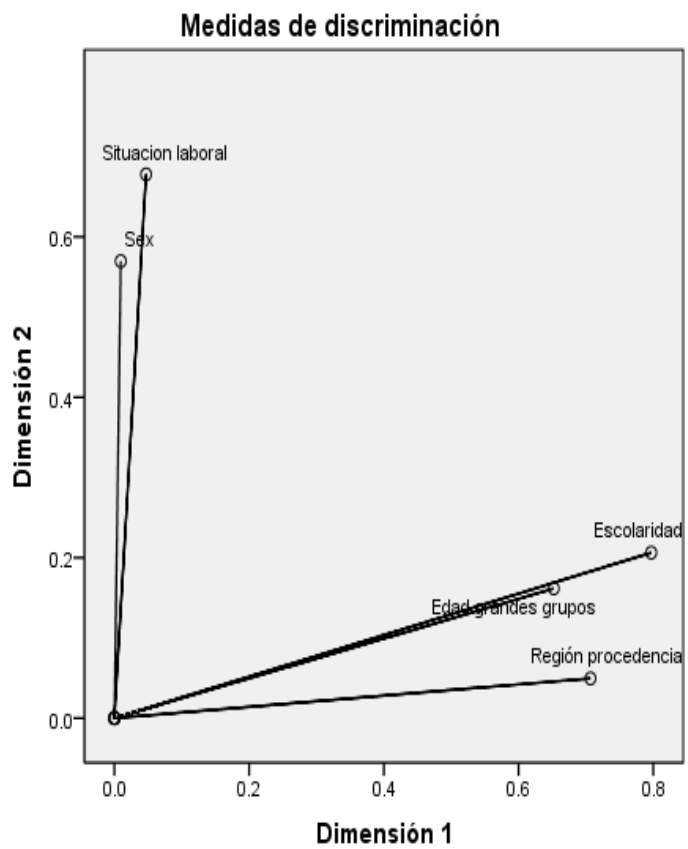


Análisis de correspondencia y medidas de discriminación en 2000

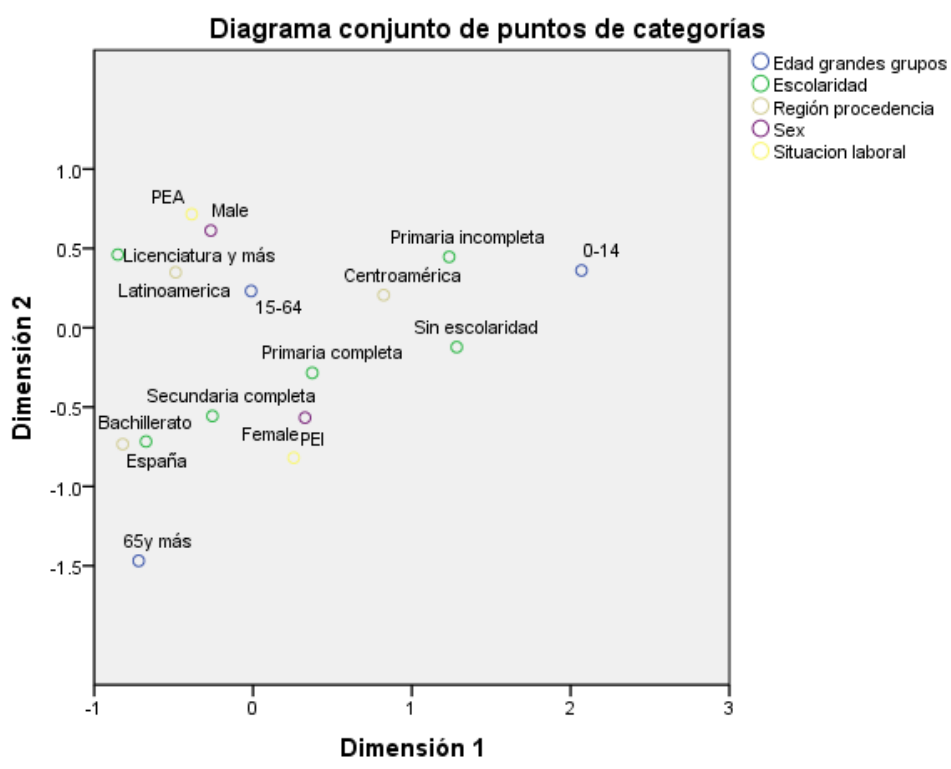

Normalización principal por variable.

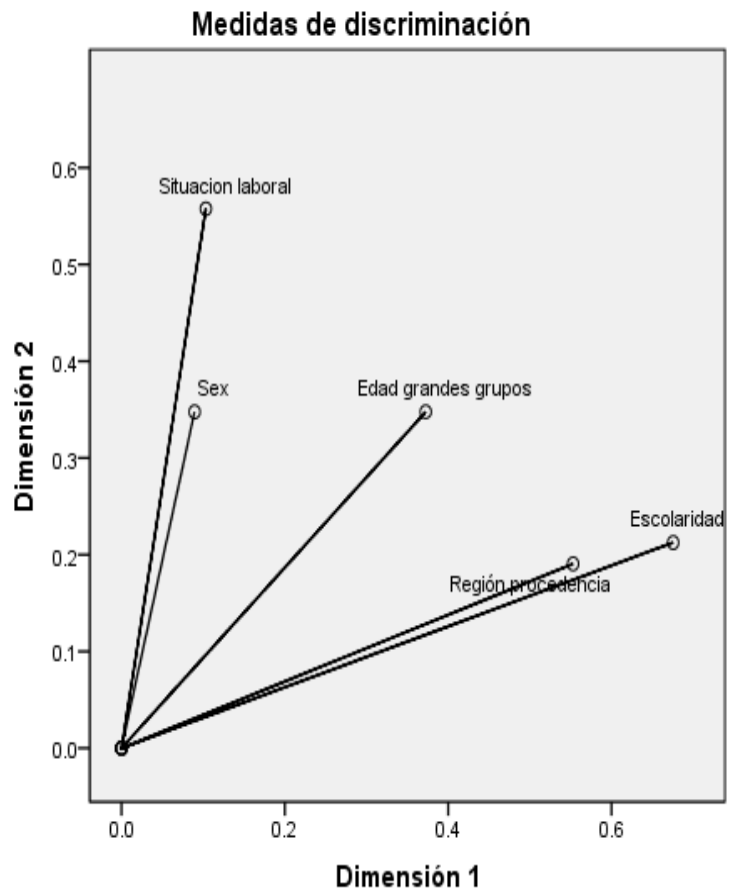

Normalización principal por variable. 
POBLACIÓN EXTRANJERA RESIDENTE EN MÉXICO.

CARACTERIZACIÓN SOCIO-DEMOGRÁFICA Y LABORAL

$1990-2010$

\section{Medidas de discriminación en 2010}

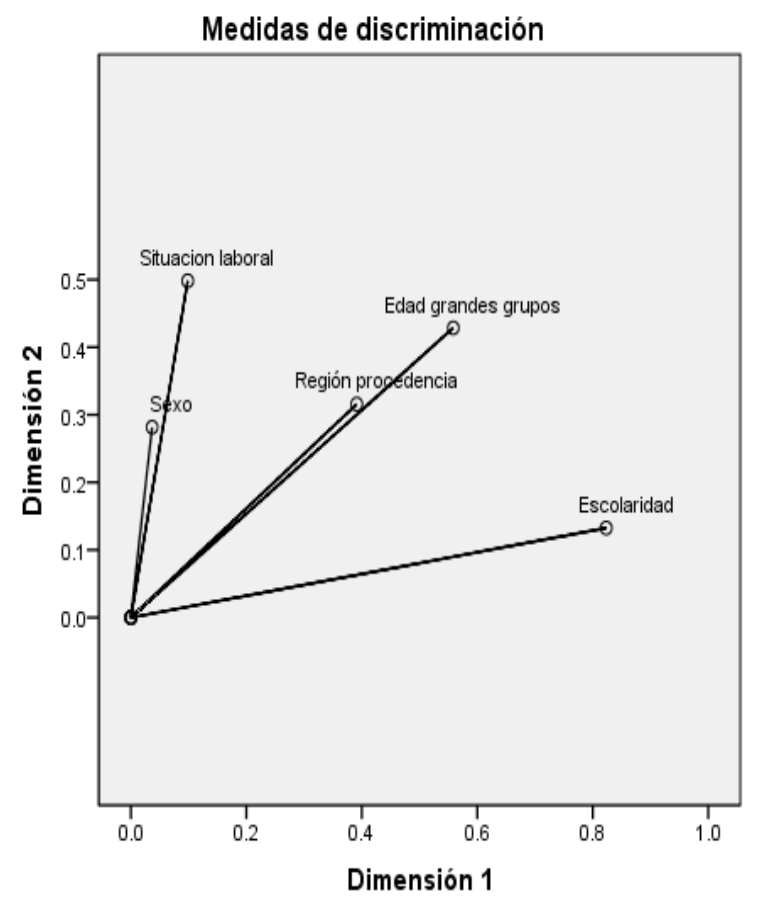

Normalización principal por variable.

Fuente: Elaboración propia con base en las muestras de los Censos de Población y Vivienda, 1990, 2000 y 2010 de INEGI 


\section{Anexo 5. Distribución porcentual de los extranjeros en México} por entidad Federativa, 1990, 2000 y 2010

\begin{tabular}{|l|r|r|r|l|r|r|r|}
\hline \multicolumn{1}{|c|}{$\begin{array}{c}\text { Entidad } \\
\text { Federativa }\end{array}$} & $\mathbf{1 9 9 0}$ & $\mathbf{2 0 0 0}$ & $\mathbf{2 0 1 0}$ & $\begin{array}{c}\text { Entidad } \\
\text { Federativa }\end{array}$ & $\mathbf{1 9 9 0}$ & $\mathbf{2 0 0 0}$ & $\mathbf{2 0 1 0}$ \\
\hline Aguascalientes & .6 & .8 & 1.1 & Morelos & 1.1 & 1.7 & 2.1 \\
Baja California & 10.1 & 12.9 & 12.9 & Nayarit & .7 & 1.1 & 1.5 \\
Baja California Sur & .5 & .7 & 1.4 & Nuevo León & 4.2 & 3.9 & 3.1 \\
Campeche & 2.4 & 1.5 & .6 & Oaxaca & .4 & .9 & 1.8 \\
Coahuila & 2.3 & 2.2 & 2.3 & Puebla & 1.9 & 2.2 & 2.2 \\
Colima & .4 & .7 & .9 & Querétaro & .6 & .7 & 1.3 \\
Chiapas & 8.1 & 3.7 & 3.3 & Quintana Roo & 2.3 & 1.7 & 1.7 \\
Chihuahua & 7.5 & 9.1 & 8.6 & San Luis Potosí & 1.2 & 1.4 & 1.6 \\
Distrito Federal & 16.3 & 11.1 & 7.7 & Sinaloa & 1.0 & 1.4 & 1.9 \\
Durango & 1.4 & 1.6 & 1.4 & Sonora & 2.8 & 3.3 & 4.3 \\
Guanajuato & 3.1 & 3.7 & 3.8 & Tabasco & .2 & .2 & .6 \\
Guerrero & .8 & 1.5 & 2.0 & Tamaulipas & 8.1 & 7.1 & 6.8 \\
Hidalgo & .2 & .6 & 1.7 & Tlaxcala & .1 & .2 & .3 \\
Jalisco & 8.8 & 10.4 & 8.1 Veracruz & 1.1 & 1.2 & 2.4 \\
México & 5.2 & 5.6 & 5.5 & Yucatán & .6 & .7 & .7 \\
Michoacán & 3.9 & 4.5 & 4.7 & Zacatecas & 2.1 & 1.9 & 1.8 \\
\hline
\end{tabular}

Fuente: Elaboración propia con base en las muestras de los Censos de Población y Vivienda, 1990, 2000 y 2010 de INEGI. 